\title{
Macular laser photocoagulation guided by spectral-domain optical coherence tomography versus fluorescein angiography for diabetic macular edema
}

\author{
This article was published in the following Dove Press journal: \\ Clinical Ophthalmology \\ 12 May 2011 \\ Number of times this article has been viewed
}

\author{
Roberto Gallego-Pinazo ${ }^{1,2}$ \\ Ana Marina Suelves- \\ Cogollos' \\ Rosa Dolz-Marco' \\ J Fernando Arevalo3 \\ Salvador García-Delpech' \\ J Luis Mullor ${ }^{4}$ \\ Manuel Díaz-Llopis 1,2,5 \\ 'Department of Ophthalmology, \\ Hospital Universitario La Fe, Valencia, \\ Spain; ${ }^{2}$ Centro de Investigación \\ Biomédica en Red de Enfermedades \\ Raras, Valencia, Spain; ${ }^{3}$ Retina \\ and Vitreous Service, Clinical \\ Ophthalmology Center, Caracas, \\ Venezuela; ${ }^{4}$ Unit of Experimental \\ Ophthalmology, Hospital \\ Universitario La Fe, Valencia, Spain; \\ ${ }^{5}$ University of Valencia, Faculty of \\ Medicine, Valencia, Spain
}

Background: The aim of this study was to compare the efficacy of spectral-domain optical coherence tomography (SD-OCT) and fluorescein angiography (FA) in the guidance of macular laser photocoagulation for diabetic macular edema.

Methods: This was a prospective interventional clinical comparative pilot study. Forty eyes from 24 consecutive patients with diabetic macular edema were allocated to receive laser photocoagulation guided by SD-OCT or FA. Best-corrected visual acuity (BCVA), central macular thickness, and retinal volume were assessed at baseline and two months after treatment.

Results: Subjects treated using FA-guided laser improved BCVA from the logarithm of the minimum angle of resolution (logMAR) $0.52 \pm 0.2$ to $0.37 \pm 0.2(P<0.001)$, and decreased mean central macular thickness from $397.25 \pm 139.1$ to $333.50 \pm 105.7 \mu \mathrm{m}(P<0.001)$ and retinal volume from $12.61 \pm 1.6$ to $10.94 \pm 1.4 \mathrm{~mm}^{3}(P<0.001)$. Subjects treated using SD-OCT guided laser had improved BCVA from $0.48 \pm 0.2$ to $0.33 \pm 0.2 \log \mathrm{MAR}(P<0.001)$, and decreased mean central macular thickness from $425.90 \pm 149.6$ to $353.4 \pm 140 \mu \mathrm{m}(P<0.001)$ and retinal volume from $12.38 \pm 2.1$ to $11.53 \pm 1.1 \mathrm{~mm}^{3}(P<0.001)$. No significant differences between the groups were found in two-month BCVA $(P=0.505)$, two-month central macular thickness $(P=0.660)$, or two-month retinal volume $(P=0.582)$.

Conclusion: The short-term results of this pilot study suggest that SD-OCT is a safe and effective technique and could be considered as a valid alternative to FA in the guidance of macular laser photocoagulation treatment for diabetic macular edema.

Keywords: spectral-domain optical coherence tomography, fluorescein angiography, macular laser photocoagulation, diabetic macular edema

\section{Introduction}

Macular laser photocoagulation is the gold standard therapy for diabetic macular edema, being the only treatment with the first level of evidence. ${ }^{1}$ It has been optimized by directing the laser spots to the leaking areas shown on fluorescein angiography (FA). ${ }^{2}$ However, FA is associated with severe potential risks. Gastrointestinal disturbances, mainly nausea and vomiting, are the most frequent adverse reactions during FA, which appear in up to $10 \%$ of these procedures. ${ }^{3}$ Cases of pulmonary edema, myocardial infarction, or anaphylactic shock have also been reported during FA. ${ }^{4-6}$ In addition to these risks, FA may be a time-consuming procedure when peripheral veins are difficult to cannulate, and this enhances patient discomfort.

On the other hand, using spectral-domain optical coherence tomography (SD-OCT), retinal images with axial resolutions of about $5 \mu \mathrm{m}$ can be obtained and displayed
Correspondence: Roberto Gallego-Pinazo Avenida Campanar, 2I 46009,

Valencia, Spain

Tel +3465995 4094

Email robertogallego@comv.es 
as a three-dimensional color-coded map superimposed and aligned on macular retinography. Vascular leakage in diabetic retinopathy is the source of increased retinal thickness and subsequent macular edema. ${ }^{7}$ Whereas FA offers information about the leaking areas within the macular area responsible for thickening of the retina, SD-OCT shows those thickened areas in the map resulting from leakage of vessels. We hypothesized that effective macular laser photocoagulation can be applied, obtaining indirect information of the points where macular laser treatment should be precisely placed utilizing SD-OCT, without exposing the patient to the potential risks of FA and with an image acquisition process that takes a few seconds. The aim of this study was to compare the efficacy of SD-OCT and FA in the guidance of macular laser photocoagulation for the treatment of diabetic macular edema.

\section{Materials and methods}

This was a prospective, interventional, comparative, pilot clinical study that included 40 eyes from 24 consecutive patients with diabetic macular edema. The diagnosis was sustained by fundus examination, FA, and SD-OCT (HD-OCT Cirrus $^{\circledR}$ and Carl Zeiss Meditec ${ }^{\circledR}$, Dublin, CA). Inclusion criteria were: clinically significant diabetic macular edema as defined by the Early Treatment Diabetic Retinopathy Study (ETDRS); ${ }^{8}$ significant elevation of the retina topographically mapped in a color code, with red (400-500 $\mu \mathrm{m})$ and white $(>500 \mu \mathrm{m})$ indicating a definitely thickened area as measured by OCT; any loss of visual acuity; and macular vessel leakage on FA. Exclusion criteria were: proliferative diabetic retinopathy; severe ischemia which made reasonable the application of panretinal photocoagulation; intravitreal injection of vascular endothelial growth factor A inhibitors at any time; intravitreal or sub-Tenon's corticosteroid treatment within the previous six months; laser treatments within the previous three months; angiographic evidence of macular ischemia; presence of retinal disease other than diabetic retinopathy; evidence of uncontrolled diabetes (glycosylated hemoglobin $>8 \%$ ), systemic arterial hypertension (systolic $>150 \mathrm{mmHg}$, diastolic $>100 \mathrm{mmHg}$ ); smoking; and insufficient mydriasis or unclear media limiting the possibility of obtaining accurate retinograms. Approval was obtained from the institutional ethics committee, and informed consent was obtained for the study. In addition, this study was performed in accordance with the ethical standards laid down in the Declaration of Helsinki.

As soon as the diagnosis was confirmed by OCT and FA, all patients were treated with macular photocoagulation.
Eyes were selected to receive laser with argon following the ETDRS guidelines guided by FA or OCT in a 1:1 ratio. Whereas in FA-guided photocoagulation the laser spots were placed within the leaking areas showed in the angiogram (Figure 1), the laser spots in OCT-guided photocoagulation were placed within the thickened areas provided by the retinal thickness map obtained with the macular cube $512 \times 128$ acquisition protocol for the HD-OCT Cirrus ${ }^{\circledR}$ (Figure 2). All laser treatments were done by the same clinician (RGP), who was provided only OCT or FA (depending on the group studied) in order to guide the therapy.

All patients had a follow-up visit at two months. The follow-up examination included best-corrected visual acuity (BCVA) as measured by ETDRS charts (converted to the logarithm of the minimum angle of resolution [logMAR], and Snellen equivalent) and measurement of central macular thickness and retinal volume by SD-OCT. All patients attended the follow-up examination during the study. The main outcome parameters were BCVA, macular thickness, and retinal volume, as measured by SD-OCT.

Statistical analysis was performed using commercially available software (SPSS for Windows, version 13.0, SPSS Inc, Chicago, IL). The data were confirmed to distribute normally and therefore are presented as the mean \pm standard deviation. To compare the measurements taken at baseline with those obtained at follow-up, the parametric Student's $t$-test for paired samples was performed. The level of significance was 0.05 (two-sided) for all statistical tests.

\section{Results}

\section{Baseline patient characteristics}

The mean age of the study population was $62.17 \pm 9.0$ years (15 males and nine females). Mean BCVA was $0.50 \pm 0.2$ $\log$ MAR $(0.36 \pm 0.16$ Snellen acuity). Mean central macular thickness was $425.90 \pm 149.6 \mu \mathrm{m}$, and mean retinal volume was $12.00 \pm 1.8 \mathrm{~mm}^{3}$.

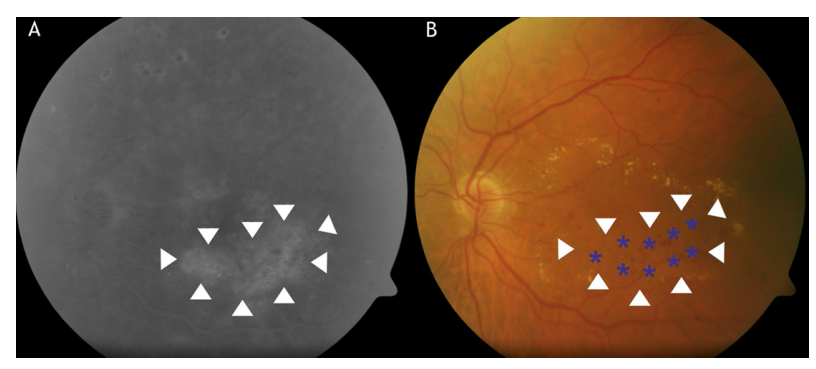

Figure I Example of fluorescein angiography guidance of macular laser photocoagulation (A) showing the leaking area of the macula (surrounded by arrowheads). The equivalent color fundus photograph (B) is used to show the laser spot location mapping (blue asterisks). 
Table I Baseline and endpoint characteristics of patients assigned to macular laser photocoagulation guided by fluorescein angiography findings

\begin{tabular}{|c|c|c|c|c|c|c|c|c|c|}
\hline \multirow[t]{2}{*}{ Patient no } & \multirow[t]{2}{*}{ Gender } & \multirow[t]{2}{*}{ Age } & \multirow[t]{2}{*}{ Eye no } & \multicolumn{2}{|c|}{ BCVA (logMAR) } & \multicolumn{2}{|c|}{$\mathrm{CMT}(\mu \mathrm{m})$} & \multicolumn{2}{|l|}{$\mathbf{R V}\left(\mathrm{mm}^{3}\right)$} \\
\hline & & & & Baseline & Endpoint & Baseline & Endpoint & Baseline & Endpoint \\
\hline I & $\mathrm{F}$ & 62 & I & 0.4 & 0.4 & 301 & 275 & 10.9 & 10.1 \\
\hline \multirow[t]{2}{*}{2} & $\mathrm{~F}$ & 67 & 2 & 0.2 & 0.2 & 334 & 344 & 11.0 & 10.9 \\
\hline & & & 3 & 0.3 & 0.3 & 424 & 396 & 10.6 & 10.5 \\
\hline 3 & $\mathrm{~F}$ & 56 & 4 & 0.2 & 0.1 & 244 & 213 & 8.6 & 8.4 \\
\hline \multirow[t]{2}{*}{4} & $\mathrm{~F}$ & 51 & 5 & 0.7 & 0.4 & 170 & 164 & 11.2 & 9.6 \\
\hline & & & 6 & 0.5 & 0.5 & 195 & 180 & 11.7 & 11.9 \\
\hline \multirow[t]{2}{*}{5} & $M$ & 62 & 7 & 0.5 & 0.4 & 272 & 244 & 10.6 & 10.6 \\
\hline & & & 8 & 0.5 & 0.4 & 387 & 321 & 11.3 & 10.6 \\
\hline 6 & $M$ & 54 & 9 & 0.7 & 0.5 & 439 & 298 & 14.4 & 13.1 \\
\hline \multirow[t]{2}{*}{7} & $M$ & 71 & 10 & 0.8 & 0.5 & 740 & 589 & 13.6 & 11.9 \\
\hline & & & II & 0.4 & 0.2 & 567 & 344 & 12.8 & 10.9 \\
\hline \multirow[t]{2}{*}{8} & $\mathrm{~F}$ & 72 & 12 & 0.3 & 0.1 & 353 & 290 & 11.6 & 10.7 \\
\hline & & & 13 & 0.5 & 0.5 & 422 & 413 & 11.3 & 10.6 \\
\hline \multirow[t]{2}{*}{9} & $M$ & 69 & 14 & 0.5 & 0.3 & 375 & 327 & 10.6 & 10.3 \\
\hline & & & 15 & 0.5 & 0.3 & 396 & 316 & 10.5 & 10.1 \\
\hline \multirow[t]{2}{*}{10} & $M$ & 48 & 16 & 0.4 & 0.4 & 472 & 493 & 12.8 & 12.8 \\
\hline & & & 17 & I & 0.7 & 579 & 369 & 14.1 & 13.4 \\
\hline \multirow[t]{2}{*}{ II } & $M$ & 66 & 18 & 0.4 & 0.2 & 357 & 297 & 10.7 & 9.5 \\
\hline & & & 19 & 0.5 & 0.2 & 352 & 303 & 9.8 & 9.6 \\
\hline 12 & $M$ & 61 & 20 & 1 & 0.7 & 566 & 494 & 14.1 & 13.2 \\
\hline
\end{tabular}

Abbreviations: FA, fluorescein angiography; F, female; M, male; BCVA, best-corrected visual acuity; CMT, central macular thickness; RV, retinal volume.

\section{FA-guided macular photocoagulation group}

Twenty eyes from 12 patients were assigned to this group. Mean age was $61.6 \pm 7.9$ (seven males and five females), mean BCVA was $0.52 \pm 0.2 \log$ MAR $(0.35 \pm 0.2$ Snellen acuity), mean central macular thickness was $397.25 \pm 139.1 \mu \mathrm{m}$, and mean retinal volume was $12.61 \pm 1.6 \mathrm{~mm}^{3}$. Two months after the initial laser treatment, mean BCVA was $0.37 \pm 0.2 \log$ MAR $(0.47 \pm 0.2$ Snellen acuity), mean central macular thickness was $333.50 \pm 105.7 \mu \mathrm{m}$, and mean retinal volume was $10.94 \pm 1.4 \mathrm{~mm}^{3}$. Statistically significant $(P<0.001)$ differences were found between pre- and postlaser treatment measurements of retinal volume, BCVA, and central macular thickness. Baseline characteristics and postlaser outcomes in the FA-guided macular photocoagulation group are summarized in Table 1.

\section{OCT-guided macular photocoagulation group}

Twenty eyes from 12 patients were assigned to this group. Mean age was $62.8 \pm 10.3$ (eight males and four females), mean BCVA was $0.48 \pm 0.2 \log$ MAR ( $0.37 \pm 0.2$ Snellen acuity), mean central macular thickness was $425.90 \pm 149.6 \mu \mathrm{m}$, and mean retinal volume measured $12.38 \pm 2.1 \mathrm{~mm}^{3}$. Two months after initial laser treatment, mean BCVA was $0.33 \pm 0.2$ $\log$ MAR $(0.45 \pm 0.2$ Snellen acuity), mean central macular thickness was $353.4 \pm 140 \mu \mathrm{m}$, and mean retinal volume was $11.53 \pm 1.1 \mathrm{~mm}^{3}$. Statistically significant $(P<0.001)$ differences were found between pre- and post-laser treatment measures of retinal volume, BCVA, and central macular thickness. Baseline characteristics and post-laser outcomes in the OCT-guided macular photocoagulation group are summarized in Table 2.

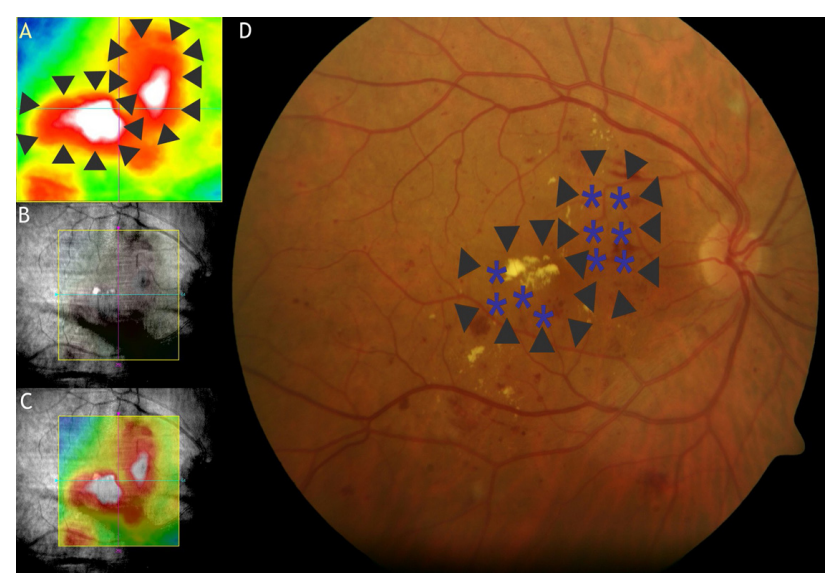

Figure 2 Example of spectral-domain optical coherence tomography (SD-OCT) guidance of macular laser photocoagulation. Retinal thickness color map (A) obtained by SD-OCT software; a fundus photograph (B) is also registered; finally, a composition of the map superimposed and aligned on the fundus image is provided automatically by SD-OCT (C). The equivalent color fundus photograph (D) is used to show the laser spot location mapping (blue asterisks) avoiding the foveal area. 


\section{Intergroup comparison}

No statistically significant differences were found between the two study groups in terms of baseline characteristics (age $P=0.774$, BCVA $P=0.647$, central macular thickness $P=0.552$, and retinal volume $P=0.151$ ). In the comparison of BCVA and OCT outcomes between the group of patients treated with FA-guided and those treated with OCT-guided macular laser photocoagulation, there were no significant differences at two months for BCVA $(P=0.505)$, central macular thickness $(P=0.660)$, or retinal volume $(P=0.582)$.

\section{Discussion}

Our results suggest that macular photocoagulation for diabetic macular edema can be guided by the retinal thickness map obtained with SD-OCT. No statistically significant differences were observed in terms of BCVA improvement or decrease in central macular thickness between patients treated following FA macular leakage and those treated only with the SD-OCT thickness map guide. To our knowledge, this is the first study to compare SD-OCT and FA as therapeutic approaches for diabetic macular edema.

Since OCT technology was first described, it has become a widely used imaging acquisition procedure in ophthalmology. ${ }^{9}$ With the former generation time-domain systems (TD-OCT), two-dimensional cross-sectional retinal images with axial resolutions of $10 \mu \mathrm{m}$ can be obtained and a color-coded macular thickness map configured by the software. Sensitivity of detecting clinically significant diabetic macular edema by measuring retinal thickness with TD-OCT is $89 \%$ and the specificity is $86 \%-96 \%$. $^{10,11}$ Currently, SD-OCT technology improves the resolution to about $5 \mu \mathrm{m}$ and acquires depth information by analyzing the interference pattern in the spectrum of mixed reflected lights.

The correlation between SD-OCT findings and FA patterns in diabetic macular edema has been the subject of several studies looking for diagnostic and histopathological clues. ${ }^{12-15}$ Thus, extrafoveal outer retinal cystic changes correspond to mild retinal edema on FA when only the outer plexiform layer is affected, and to more pronounced forms of edema when also the outer nuclear layer is affected. The severity of the extrafoveal inner retinal cystic changes showed a positive correlation with the severity of leakage on FA, and extrafoveal loss of retinal layers corresponded with capillary nonperfusion on FA. ${ }^{15}$ In addition, vitreomacular interface characteristics are clearly shown in SD-OCT, whereas FA gives poor information about these abnormalities.

Table 2 Baseline and endpoint characteristics of the patients assigned to macular laser photocoagulation guided by SD-OCT retinal thickness map

\begin{tabular}{|c|c|c|c|c|c|c|c|c|c|}
\hline \multirow[t]{2}{*}{ Patient no } & \multirow[t]{2}{*}{ Gender } & \multirow[t]{2}{*}{ Age } & \multirow[t]{2}{*}{ Eye no } & \multicolumn{2}{|c|}{ BCVA (logMAR) } & \multicolumn{2}{|c|}{$\mathrm{CMT}(\mu \mathrm{m})$} & \multicolumn{2}{|c|}{$\operatorname{RV}\left(\mathrm{mm}^{3}\right)$} \\
\hline & & & & Baseline & Endpoint & Baseline & Endpoint & Baseline & Endpoint \\
\hline 13 & $M$ & 63 & 21 & 0.8 & 0.5 & 428 & 338 & 13.9 & 12.3 \\
\hline \multirow[t]{2}{*}{14} & $\mathrm{~F}$ & 64 & 22 & 1 & 0.8 & 875 & 562 & 17.9 & 14.0 \\
\hline & & & 23 & 0.8 & 0.5 & 647 & 319 & 14.9 & 12.3 \\
\hline 15 & M & 55 & 24 & 0.4 & 0.4 & 358 & 332 & 8.8 & 8.6 \\
\hline \multirow[t]{2}{*}{16} & M & 52 & 25 & 0.7 & 0.3 & 519 & 341 & 13.7 & 12.2 \\
\hline & & & 26 & 0.4 & 0.2 & 456 & 207 & 12.8 & II.I \\
\hline \multirow[t]{2}{*}{17} & $M$ & 74 & 27 & 0.3 & 0.2 & 276 & 242 & 10.3 & 9.6 \\
\hline & & & 28 & 0.5 & 0.5 & 423 & 311 & 12.9 & 11.5 \\
\hline \multirow[t]{2}{*}{18} & $M$ & 65 & 29 & 0.5 & 0.4 & 310 & 288 & 13.7 & 12.8 \\
\hline & & & 30 & 0.4 & 0.3 & 454 & 326 & 11.3 & 10.9 \\
\hline \multirow[t]{2}{*}{19} & $\mathrm{~F}$ & 57 & 31 & 0.3 & 0.2 & 324 & 256 & 11.8 & 10.9 \\
\hline & & & 32 & 0.3 & 0.2 & 355 & 294 & 11.7 & 10.6 \\
\hline \multirow[t]{2}{*}{20} & $M$ & 41 & 33 & 0.2 & 0.1 & 278 & 219 & 12.1 & 11.7 \\
\hline & & & 34 & 0.3 & 0.3 & 296 & 234 & 10.4 & 9.9 \\
\hline \multirow[t]{2}{*}{21} & $\mathrm{~F}$ & 76 & 35 & 0.4 & 0.2 & 394 & 313 & 10.5 & 10.1 \\
\hline & & & 36 & 0.2 & 0.1 & 302 & 287 & 10.2 & 10.1 \\
\hline \multirow[t]{2}{*}{22} & $M$ & 68 & 37 & 0.7 & 0.4 & 572 & 345 & 14.5 & 11.5 \\
\hline & & & 38 & 0.7 & 0.5 & 563 & 538 & 13.2 & 12.5 \\
\hline 23 & $\mathrm{~F}$ & 63 & 39 & 0.3 & 0.1 & 335 & 315 & II.I & 9.4 \\
\hline 24 & $M$ & 75 & 40 & 0.4 & 0.3 & 346 & 331 & 11.9 & 11.0 \\
\hline
\end{tabular}

Abbreviations: SD OCT, spectral-domain optical coherence tomography; F, female; M, male; BCVA, best-corrected visual acuity; CMT, central macular thickness; $\mathrm{RV}$, retinal volume. 
Retinal ischemia in diabetic maculopathy is an important predictor of poor functional outcome. Clinical suspicion for macular ischemia may be established when visual acuity is poorer than expected by fundus examination and SD-OCT images. Fluorescein angiography is the gold standard technique to diagnose nonperfusion. However, loss of retinal layers on SD-OCT has been characterized as a specific predictive sign of capillary nonperfusion and severe ischemia. Therefore, in such cases, structural changes, as well as macular perfusion status and central retinal thickness, should be analyzed. Nowadays SD-OCT cannot replace FA for this purpose.

Limitations of our pilot study include the fact that it was nonrandomized, and it had a limited number of patients and a relatively short follow-up. However, the results were promising and suggest the need for further investigation.

The short-term results of this pilot study suggest that $\mathrm{SD}-\mathrm{OCT}$ is a safe and effective technique and could be considered as a valid alternative to FA in the guidance of macular laser photocoagulation treatment for diabetic macular edema. Although macular perfusion status does not need to be routinely assessed when evaluating diabetic patients, we suggest that a retinal thickness map should be used to plan laser spot location during the first macular photocoagulation treatment and even more in further retreatments, making use of a noninvasive and rapid technique that provides the same topographic information as FA. Evaluation of SD-OCT-guided laser photocoagulation in a multicenter randomized controlled clinical trial is warranted.

\section{Disclosure}

The authors declare no financial or proprietary interest in any of the products or techniques mentioned in this article.

\section{References}

1. Photocoagulation for diabetic macular edema. Early Treatment Diabetic Retinopathy Study Report Number 1. Arch Ophthalmol 1985;103: 1796-1806.

2. Early Treatment Diabetic Retinopathy Study Research Group. Focal photocoagulation treatment of diabetic macular edema. Relationship of treatment effect to fluorescein angiographic and other retinal characteristics at baseline: ETDRS Report Number 19. Arch Ophthalmol 1995;113:1144-1155.

3. Ellis PP, Schoenberger M, Rendi MA. Antihistamines as prophylaxis against side reactions to intravenous fluorescein. Trans Am Ophthalmol Soc. 1980;78:190-205.

4. Hess JB, Pacurariu RI. Acute pulmonary edema following intravenous fluorescein angiography. Am J Ophthalmol. 1976;82:567-570.

5. Deglin SM, Deglin EA, Chung EK. Acute myocardial infarction following fluorescein angiography. Heart Lung. 1977;6:505-509.

6. LaPiana FG, Penner R. Anaphylactoid reaction to intravenously administered fluorescein. Arch Ophthalmol. 1968;79:161-162.

7. Knudsen ST, Bek T, Poulsen PL, et al. Macular edema reflects generalized vascular hyperpermeability in type 2 diabetic patients with retinopathy. Diabetes Care. 2002;25:2328-2334.

8. Early Treatment Diabetic Retinopathy Study Research Group Treatment techniques and clinical guidelines for photocoagulation of diabetic macular edema: Early Treatment Diabetic Retinopathy Study Report Number 2. Ophthalmology. 1987;94:761-774.

9. Huang D, Swanson EA, Lin CP, et al. Optical coherence tomography. Science. 1991;254:1178-1181.

10. Goebel W, Kretzchmar-Gross T. Retinal thickness in diabetic retinopathy: A study using optical coherence tomography (OCT). Retina. 2002;22:759-767.

11. Sadda SR, Tan O, Walsh AC, et al. Automated detection of clinically significant macular edema by grid scanning optical coherence tomography. Ophthalmology. 2006;113:1187.e1-1187.e12.

12. Otani T, Kishi S. Correlation between optical coherence tomography and fluorescein angiography findings in diabetic macular edema. Ophthalmology. 2007;114:104-107.

13. Soliman W, Sander B, Hasler PW, et al. Correlation between intrarretinal changes in diabetic macular oedema seen in fluorescein angiography and optical coherence tomography. Acta Ophthalmol. 2008;86: 34-39.

14. Bolz M, Ritter M, Schneider M, et al. A systematic correlation of angiography and high-resolution optical coherence tomography in diabetic macular edema. Ophthalmology. 2009;116:66-72.

15. Yeung L, Lima CV, Garcia P, et al. Correlation between spectral domain optical coherence tomography findings and fluorescein angiography patterns in diabetic macular edema. Ophthalmology. 2009;116: 1158-1167.
Clinical Ophthalmology

\section{Publish your work in this journal}

Clinical Ophthalmology is an international, peer-reviewed journal covering all subspecialties within ophthalmology. Key topics include: Optometry; Visual science; Pharmacology and drug therapy in eye diseases; Basic Sciences; Primary and Secondary eye care; Patien Safety and Quality of Care Improvements. This journal is indexed on

\section{Dovepress}

PubMed Central and CAS, and is the official journal of The Society of Clinical Ophthalmology (SCO). The manuscript management system is completely online and includes a very quick and fair peer-review system, which is all easy to use. Visit http://www.dovepress.com/ testimonials.php to read real quotes from published authors. 